\title{
Applying a Geographical Information System (GIS) to the study of the growth of benthic clonal organisms
}

\author{
Joaquim Garrabou* \\ Dpt. d'Ecologia, Fac. Biologia, Univ. Barcelona, Avgda. Diagonal 645, E-08028 Barcelona, Spain
}

\begin{abstract}
Geographical Information Systems (GIS) were applied to study the growth of benthic encrusting clonal organisms. Routine GIS overlaying procedures were used to merge referenced specimen outlines from different time steps into a single image. From the resulting composite image the GIS automatically calculated independent growth (i.e. net area gained) and shrinkage (i.e. net area lost) rates for any desired time period. This method provided automatic and reliable data for estimating the growth and shrinkage rates of benthic clonal organisms. The availability of GIS software for multiple platforms allows application of this method at an acceptable cost; a moderate period of training is necessary to learn how to perform the analysis necessary to obtain growth and shrinkage rates. The application of GIS technology will help improve the study of the complex growth patterns exhibited by benthic clonal organisms.
\end{abstract}

KEY WORDS: Benthic clonal organisms - Geographical Information System - GIS · Growth rates

\section{INTRODUCTION}

Clonal organisms predominate in many sublittoral benthic habitats (Jackson 1977). Despite their importance, studies on the life-history parameters of clonal organisms are relatively scarce (Hughes \& Cancino 1985. Hughes 1989). These organisms are generally characterised by their growth plasticity (Sebens 1987), which complicates the assessment of relevant rates for these organisms. Generally, assessment requires repeated recording of the fates of selected specimens over as much of their life-span as possible (currently several years) (Ayling 1983, Hughes \& Cancino 1985, Hughes \& Jackson 1985, Turon \& Becerro 1992, Fabricius 1995). Present analytical methods tend to be highly time-consuming, since almost all data treatment involves manual processing. These methodological requirements underlie the relative paucity of studies

- Present address: Dept of Zoology, University of Maryland at College Park, College Park, Maryland 20742, USA.

E-mail: garrabou@wam.umd.edu dealing with the life-history parameters of clonal organisms. For that reason, new methodological approaches to facilitate and automate data acquisition are needed for compilation of a body of knowledge on the life histories of clonal organisms. Furthermore, since clonal organisms are important components of most sublittoral communities increasing existing knowledge of their life-history parameters would lead to a better understanding of the organization of such communities.

In clonal organisms, capabilities for reproduction, competition, regeneration and survival should increase with size (Jackson 1977, Hughes \& Cancino 1985). Therefore, growth dynamics, which should strongly contribute to the actual size of specimens, becomes one of the most important classes of parameters to be considered when trying to understand the other life-history traits of clonal organisms. However, studies on growth dynamics of these organisms are generally lacking. Growth rates are commonly obtained from the differences in specimen size (e.g. area, maximum diameter, or linear growth) recorded at different times (e.g. Dayton 1979, Bak et al. 1981, Turon \& 
Becerro 1992). However, since degrowth (recession from a formerly occupied space), partial mortality (loss of part of a specimen through physical or biological disturbance), fusion (union of 2 or more ramets - units capable of independent existence), and fission or fragmentation (splitting of a single specimen into 2 or more ramets) processes may operate on different parts of the same specimen affecting the size of the specimen concurrently with growth (gaining of new space), the growth rates obtained from differences in specimen size may not convey all the information on the growth dynamics. Therefore, methods that separately quantify the processes affecting specimen size are desirable not only to obtain more accurate growth rates but also to obtain other relevant rates, such as degrowth (or partial mortality). These methods should obtain measures over the entire specimen, noting the changes due to all processes affecting specimen size.

This investigation presents application of Geographical Information System (GIS) technology to the study of the growth of clonal organisms. GIS technological capabilities offer an automated method for studying temporal changes in specimen area over the entire specimen, thus offering a good opportunity to improve studies of the growth of clonal organisms. Routine GIS procedures can overlay the drawings (i.e. outlines) of selected specimens at different time steps and calculate changes in specimen area from the resulting new image. The area changes correspond to growth (i.e. net area gained) or shrinkage (i.e. net area lost, irrespective of the cause [degrowth or partial mortality]). The method therefore automatically provides reliable data on growth and shrinkage rates for clonal organisms. Moreover, as the GIS overlays the entire specimen area, the rates obtained take into account fusion and fission processes occurring over a given period of time.

Basically, a GIS is software designed to deal with a spatially explicit database, i.e. an automated link between data and their spatial location. Moreover, GIS software incorporates a wide range of routine tools and facilities to manage a digitized spatial database (entry, storage, transformation, measurement, display, etc.). The use of GIS has lately become widespread, concurrently with the availability of inexpensive yet powerful computers. GIS applications have centered on land management and landscape ecology (Turner 1989, Johnson 1990), although the method's analytical capabilities have been applied to such different subjects as the study of the growth of roots or insect damage to leaves, among others (Johnston 1992).

The object of this paper is to describe the application of GIS procedures in the study of the growth of clonal species using specimens of different species. Further specimens of the same and several other species have been monitored as part of a study of the growth and survival of clonal metazoans in communities in the Medes Islands (NE Spain); results of these studies are reported elsewhere (Garrabou 1997).

\section{MATERIALS AND METHODS}

This section is organized in 5 parts concerning the 5 basic steps be followed in the application of the GIS method to quantify growth in clonal organisms. These parts contain both the description of the procedures followed and information regarding the tests and warnings required to use the method properly.

(1) Taking the photographs. The study was carried out in the Medes Islands Protected Area (Spain, NW Mediterranean) on a north-facing sublittoral wall. Several sampling sites were selected on the sublittoral wall in order to monitor the fates (growth, degrowth, partial mortality, mortality, and recruitment) of specimens of different species. At each site, 2 tube clips were attached to the rock by means of screws, using holes previously filled with putty. The tube clips were used to support the camera in a fixed position. A Nikonos-V camera equipped with $28 \mathrm{~mm}$ and close-up lenses and 2 electronic strobes (to reduce shadows) were fitted with a custom-built camera setup and attached to the tube clips on each sampling date (Fig. 1). The lens equipment used allowed monitoring of surface areas of $310 \mathrm{~cm}^{2}$ and identification of organisms larger than $4 \mathrm{~mm}^{2}$ in area.

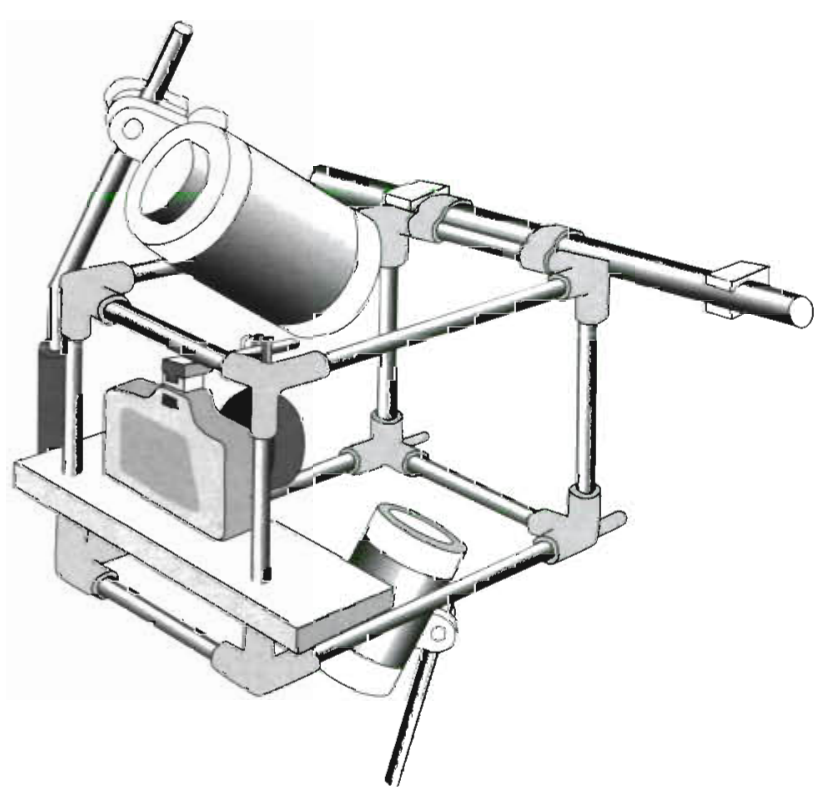

Fig. 1. Camera setup for monitoring permanent sampling sites 
Since the GIS method is based on overlaying outlines of the same photograph taken at different times (see below), it is self-evident that inaccurate reproduction of photographs could lead to important bias, mainly due to parallax problems. Testing the accuracy of the reproducibility of monitored shots is, thus, an important step. In this study the possible effect of repositioning the setup on specimen area and perimeter measurements was tested. Three photographs of 4 different plots were taken, repositioning the setup 3 times in the same day. From the 4 plots a set of $30 \mathrm{spec}-$ imens of different species were selected. For each photograph 3 outlines of the selected specimens were traced and their area and perimeter were calculated. To test the reproducibility of photographs data on area and perimeter for each selected specimen were analyzed with 1-way ANOVA test (factor: photograph). The results denoted non-significant differences in specimen area and perimeter except in 1 case for perimeter, indicating good reproducibility of the shots (Appendices 1 \& 2).

(2) From photographs to drawings. The slides were projected using an inverse projector and patches corresponding to the selected specimens were outlined by tracing on acetate sheets; other specimens or substrate marks that could be used as references were also traced. A single label was used to identify each monitored specimen. For each camera shot the outlines were referenced using a common coordinate system (3 coordinate points). Specimen position and characteristic marks were used during this process to minimize possible alignment errors.

One of the main problems in obtaining the specimens' outlines is the occurrence of seasonal epibiotic episodes (e.g. algae). During such episodes it may be difficult to trace the outline of the specimens, since margins may not be visible in the photographs. In such cases in this study the visible margin was outlined and the non-visible margin was assumed to be identical to the previous outline (by manually overlaying the previous outline). Thus, no changes in area were attributed to parts attacked by epibionts, yielding 'conservative' growth and shrinkage rates, since the parts of the specimen covered by the epibiont could have undergone growth or shrinkage. However, since seasonal epibiosis is a short-term phenomenon, non-visible margins usually became visible again at later dates, and any changes could be quantified in later rates.

Boundary definition may affect the calculations of growth and shrinkage rates because it may hinder accurate tracing of specimen outlines. Benthic clonal species may display boundaries that are sharply defined to indistinct. Furthermore, problems relating to photographic quality, shadows, presence of epi- bionts, competitive interactions, etc. can also obscure the specimens' outline. To study this effect on data acquisition of specimen areas and perimeters, we used the analysis performed to test the effects of setup repositioning (see point 1 'Taking the photographs'). The selected specimens $(n=30)$ were pooled into 1 of 3 categories according to sharpness of boundary definition: I, sharp boundary in $90 \%$ of their perimeter; II, sharp boundary in 50 to $90 \%$ of their perimeter; and III, sharp boundary in 10 to $50 \%$ of their perimeter The coefficient of variation of the area and perimeter of each specimen was calculated using MS residual (obtained from the ANOVA analysis carried out above). In this way only the variability due to the outline process is taken into account. Overall, a clear pattern was found: specimens in category I exhibited lower variability (CV -2 to $6 \%$ ) than specimens within category III (CV -3 to $24 \%$ ) for both measured variables (Appendix 3). Therefore, it is recommendable to consider only species with sharp boundaries when using the GIS method.

(3) From drawings to computer images. The drawings were scanned (gray scale mode with 100 dpi resolution, scanner Epson GT-8000) in a IBM-PC system. The resulting raster images (TIFF format) were imported to a Sun workstation (Unix operating system) where all image processing and analysis were carried out. The images were imported into IMAT, a program developed by the Serveis Cientifico-Tècnics of the University of Barcelona, where they were submitted to 3 distinct processes. Firstly the images were converted to binary images (black and white): the conversion took into account the pixel intensity, in such a way that if the pixel intensity was below or above a critical value it was converted to black or white respectively (binarization process). The result of this process was an image of the patches clearly outlined. Secondly, all lines were thinned to a standard width, in this way we avoided errors in area or perimeter estimations (thinning process). Thirdly, all outlines were automatically numbered and recognized by the program as distinct objects (this is an essential condition to vectorize the image). After these processes the images were spatially referenced, introducing the values ( $x$ and $y$ ) of the 3 coordinate points. Finally, the images were vectorized and exported to file format compatible with the Arc/Info Geographical Information System (GIS) program.

(4) Importing images into GIS. Routine Arc/Info GIS software procedures were used to import the vectorized images, label the patches (i.e. specimens), and update, modify, and store data for each image. Each GIS image has an associated database. This database contains information on area and perimeter as well as a specimen identifier for each spatial ele- 
ment (i.e. specimens). The spatio-temporal database model proposed by Kienast (1993) was applied to our time series of images. The main feature of this database model is that it stores the specimen identifiers in a field with a different name (e.g. the corresponding time step) for each image from the same photograph.

Outlines of 2 specimens of the sponge Crambe crambe (Schmidt) were chosen to illustrate the use of the GIS in growth measurements. These specimens are good examples of the high plasticity of growth shown by this sponge in particular as well as by clonal organisms in general. The sponge $C$. crambe employs an encrusting growth habit, and thus changes in specimen area provide good estimates of growth. The outlines were obtained from photographs taken from August 1993 to August 1995 at 2 to 3 mo intervals. The 2 specimens investigated were located at a depth of $10 \mathrm{~m}$.

(5) Obtaining growth rates with GIS. Routine overlay procedures (union command) were used to merge all images into 1 composite image (i.e. a unified cover) (Fig. 2). As all images from the same photograph were in the same coordinate system, overlay procedures overlapped the positions of specimens in time, resulting in division of the image into new polygons. Depending on changes in specimen areas, more or fewer polygons are generated; the more changes in area and shape, the more polygons are generated. Each polygon in the composite new image contains information about which specimens (i.e. label) have occupied the polygon over time. For instance, a composite image obtained from a specimen that underwent neither growth nor shrinkage during a study period (i.e. no changes in specimen area) would have only 1 polygon with the specimen identifier, and this polygon would have the same identifier for all time steps. Conversely, a composite image obtained from a specimen with active growth or shrinkage (i.e. changes in specimen area) would have several polygons having or lacking the specimen identifier. Furthermore in this case most of the polygons would have the specimen identifier only for certain time steps. Net growth can easily be calculated as the area gained by a specimen between 2 time steps which is the sum of the areas of all polygons in time step $i$ that did not have specimen identifier and in time step $i+1$ that had specimen identifier; or correspondingly net shrinkage which is the area lost by a specimen between 2 time steps obtained from applying the inverse criteria (Fig. 2). The area and perimeter for each specimen were also calculated from the original images (i.e. for a single time step).

The data contained in the composite image were used as explained above to calculate independent net

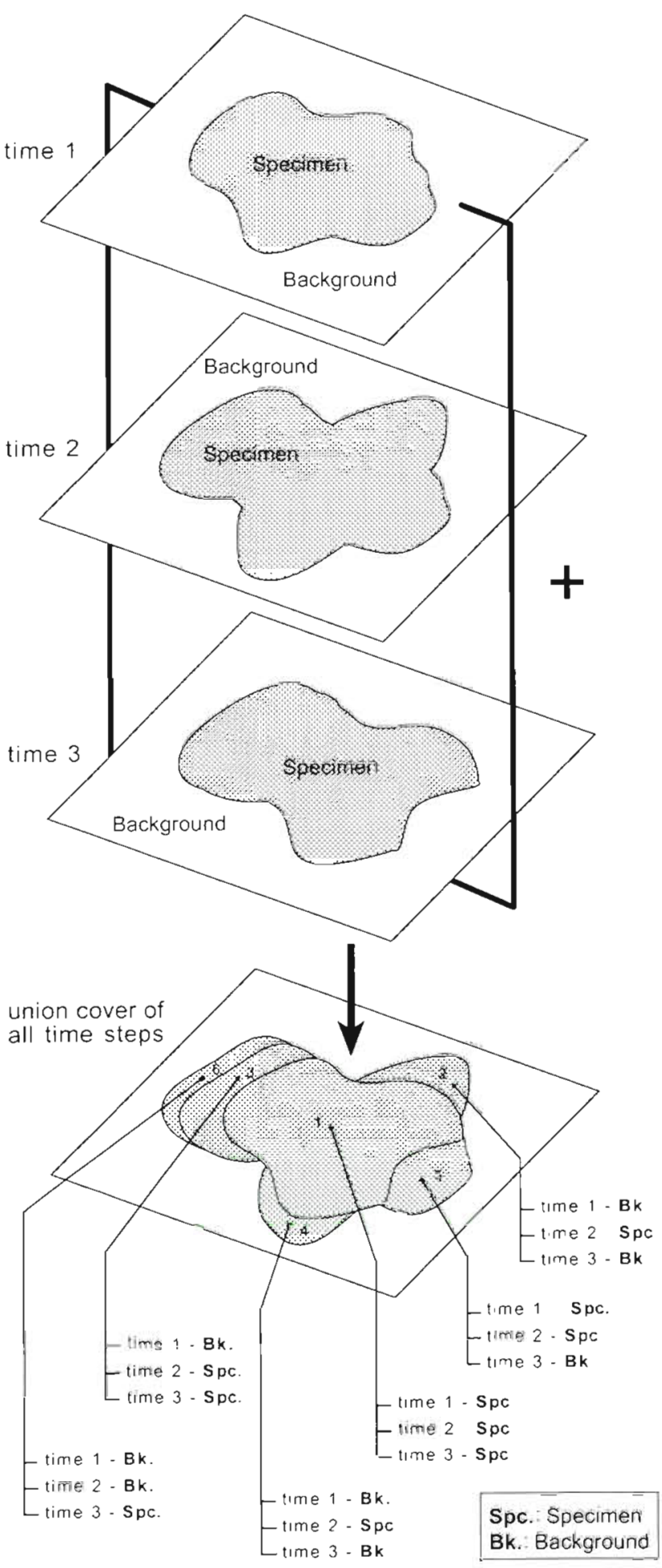

Fig. 2. Outlines of a hypothetical colony of an encrusting organism at 3 time steps, and the resulting unified cover obtained by overlaying the 3 mages Each polygon in the unlfied cover is identified by tıme-stamped attroutes that allow quantification of colony growth and shrnkage over time 
Specimen 1
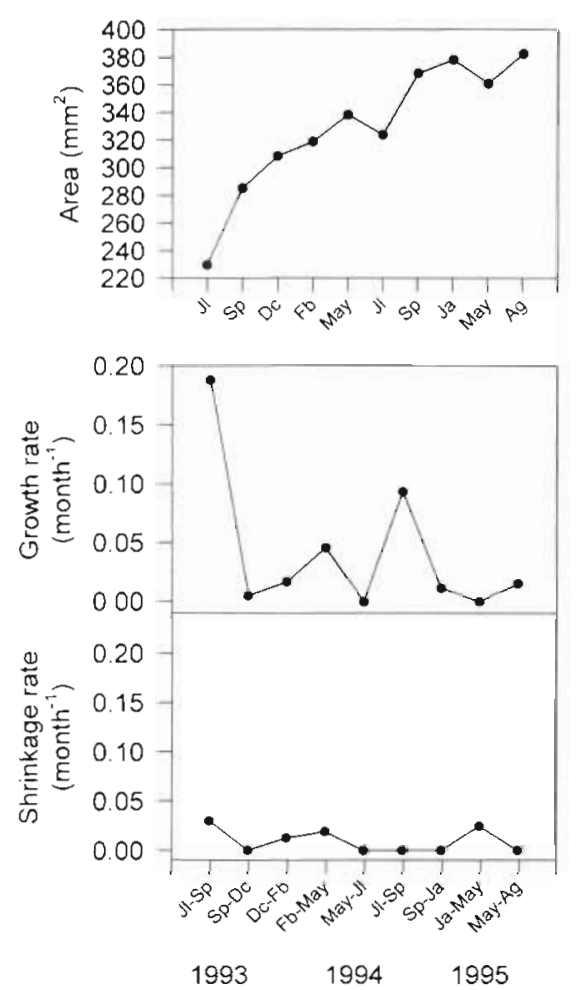

Specimen 2
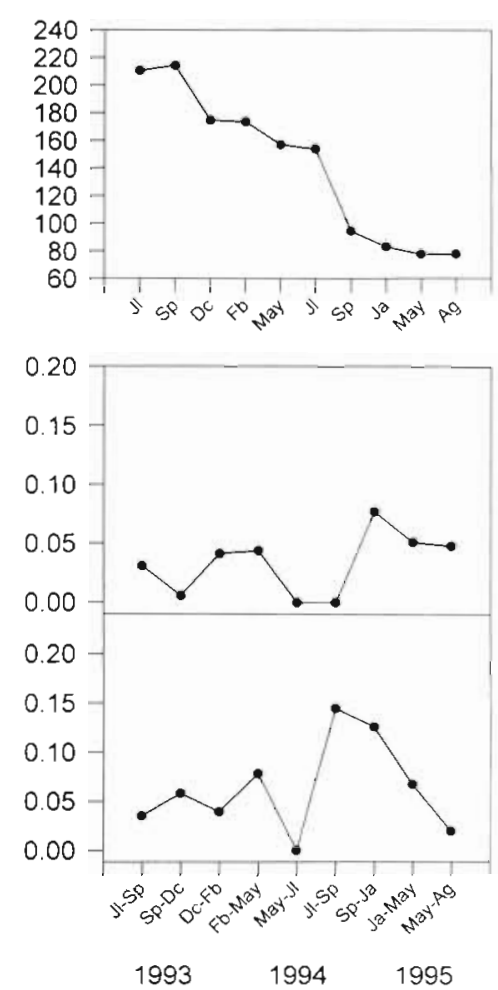

Fig. 3. Temporal changes in area and growth and shrinkage rates for 2 colonies of the sponge Crambe crambe over a 2 yr period

Three different combinations of cleaning criteria were tested. The combination selected (area $<3 \mathrm{~mm}^{2}$ and area:perimeter $<0.2$ ) showed the lowest differences in specimen area values obtained from original images and composite image after cleaning. This ensured that cleaning procedure did not bias growth measurements. Obviously the criteria have to take into account the spatial scale used (extent and resolution) and species dynamics (temporal scale), thus they have to be determined by each researcher.

\section{RESULTS}

The changes in area found for the specimens of the sponge Crambe crambe are presented in Fig. 3. The specimens exhibited contrasting trends: specimen 1 underwent a continuous increase in size over time, while specimen 2 underwent a continuous decrease in size over time (Fig. 3).

Application of GIS procedures enabled quantification of the growth and

growth and shrinkage rate for each specimen. Growth and shrinkage rates were estimated from the expression:

relative growth (or shrinkage) rate $=$

$\frac{\left(\frac{\text { area gained (or lost) between } t_{i} \text { and } t_{i+1}}{\text { area at } t_{i}}\right)}{\text { time between } t_{1} \text { and } t_{i+1} \text { (in months) }}$

Prior to these calculations polygons in the composite image with a surface area of less than $3 \mathrm{~mm}^{2}$ and an area to perimeter ratio lower than 0.2 were eliminated from the composite image (i.e. unified cover). These polygons are considered sliver polygons resulting from unavoidable minor tracing and alignment errors and could contribute to spurious changes in area being detected and being taken into account in growth or shrinkage rates, yielding inaccurate values; therefore they have to be eliminated. The criteria applied to identify the sliver polygons is thus a key point of the GIS method. In this study the criteria were determined by comparing the area values of 63 specimens calculated for the original outlines with the specimens' area values back-calculated from the composite images 'cleaned' using different combinations of polygon area and the area:perimeter ratio values. shrinkage rates for the specimens studied. Growth rates for specimen 1 peaked in July to September 1993 and $1994\left(0.19\right.$ and $0.10 \mathrm{mo}^{-1}$ respectively); the rest of the time growth rates were around $0.05 \mathrm{mo}^{-1}$ (Fig. 3). Specimen 2 showed lower growth rates (rarely higher than $0.05 \mathrm{mo}^{-1}$ ) over the entire study period (Fig. 3). Shrinkage rates for specimen 1 were lower than 0.05 $\mathrm{mo}^{-1}$ over the entire period (Fig. 3). Conversely, specimen 2 showed high shrinkage rates over the period (except in spring-summer 1994), with a peak in summer-autumn 1994, attaining a shrinkage rate of 0.15 mo ') (Fig. 3).

Thus, specimen 1 increased in size by means of seasonal growth in summer-autumn in the years 1993 and 1994 (i.e. high growth rates in those periods) and maintained moderate growth rates over the remainder of the study period. Shrinkage rates for specimen 1 were low. Specimen 2 decreased in size, evidenced by a continuous loss in area, and thus maintained high shrinkage rates throughout the study period. Despite the continuous decrease in size, growth rates for specimen 2 were nonetheless higher than 0 for most sampling intervals, although the growth rate values were never higher enough to compensate for the area lost. 


\section{DISCUSSION}

The GIS method presented in this study proved useful in analysing the growth of specimens of the sponge Crambe crambe. GIS analysis provided satisfactory values for growth and shrinkage corresponding to the changes in size of the 2 specimens studied. Specimen 1. which increased in size during the study period, had high growth rate values and low shrinkage rate values, whereas specimen 2, which decreased in size during the study period, followed an opposing trend. Interestingly, despite the clear general trend for each specimen, growth or shrinkage rates attained null values only in a few sampling intervals. This brings home the need to employ separate measures of growth and shrinkage to better understand the growth strategies of clonal organisms.

Growth patterns similar to those exhibited by the specimens of Crambe crambe studied (with growth and degrowth episodes involving different parts of the specimens), can be found in most benthic clonal species. In general, it is recognized that clonal species growing in natural conditions are constrained by environmental factors (competition, food availability, predation, etc.) favouring differential development or recession of different parts of specimens, made possible by the characteristic growth plasticity of clonal organisms (Sebens 1987. Hughes 1989). Therefore, GIS methods can be readily applied to other clonal species.

Few studies have reported independent measures of growth and shrinkage (but see Ayling 1983, Hughes \& Jackson 1985, Sebens 1986, Nandakumar et al. 1993, Coma 1994). In such studies drawings of monitored specimens have generally been overlaid and changes in area traced manually, noting growth and shrinkage for each portion (see Sebens 1986). Despite improvements in the study of the growth strategies of clonal organisms, few studies have followed this, probably due to the time needed to verify changes in area manually. In fact, the GIS method presented in this study calculates growth and shrinkage rates by the same procedure (i.e. changes in area); however, the GIS obtains the changes in area automatically, rather than manually, for any desired time period. Therefore, application of the GIS method can facilitate data acquisition and description of the growth strategies of clonal organisms.

The growth and shrinkage rates obtained using the GIS method were calculated from the changes in specimen area covering the substratum. In general, area gained or area lost should be interpreted as production (due to specimen growth) or loss (due to dislodgment, predation, etc.) of specimen biomass. However, benthic clonal species may also reallocate their resources within the specimen, as occurs for instance in some ascidian species during fission or fusion events (e.g. Cowan 1981, Stocker 1991). In such situations growth or shrinkage does not necessarily mean new production or net loss of tissues, and therefore interpretation of the calculated growth and shrinkage rates should take into account the occurrence of resource reallocation processes in the species studied.

The GIS method presented in this study is mainly applicable to clonal organisms with 2-dimensional growth habits; this includes species with morphological habits in the form of sheets, plates, and mounds sensu Jackson (1979). These growth forms allow changes in area to be determined by overlaying the specimens' outlines for different time steps and thus to calculate growth and shrinkage rates. However, in mound-like species, this method does not provide information on vertical growth. Tree-like species with hard skeletons or growing in a 2-dimensional plane (e.g. gorgonians) can also be studied with the GIS method; the only stipulation is that the photograph must always be taken from the same angle and position. Vago et al. (1994) presented an example of a setup suitable for monitoring the growth of erect coral species. That method did not produce reliable results for soft-bodied erect species, and alternative methods should be used such as measurement of biometric parameters (e.g. basal diameter).

In conclusion, application of the GIS technology to the current (or past) monitoring programs on the growth of clonal organisms affords a good opportunity for improving their study. On one hand it provides immediate benefits in the automatic acquisition of reliable data on the growth and shrinkage of the clonal organisms and its facilities for image handing. On the other hand it does not involve substantial additional outlays, since there is a wide range of commercial GIS software available for multiple platforms (PC, Macintosh, and Unix). However, to be fully operational and to be able to obtain the results described in this study, a moderate period of training in basic GIS procedures is necessary.

Acknowledgements. The manuscript benefited from the critıcisms of J. G. Harmelin, J. D. Ros, X. Turon and M. Zabala and 4 anonymous reviewers. I particularly thank my doctoral advisor, Dr M. Zabala, for his support and advice in many phases of this study. I also thank A. Arcas, E. Sala, R. Coma, and $\mathrm{M}$. Ribes for their help throughout this project. I thank $\mathrm{J}$. L. Cuevas for all his assistance and patience during the introduction to the G.I.S and the Arc/Info program, F. Kienast for his help in applying the database model and A. Giorgio for the initial discussions on image analysis and his introduction to the IMAT program. I also thank C. Sabaté and J. Corbera for figure processing. This study was funded by the 'Direcció General de Pesca Maritima' of the 'Conselleria d'Agricultura Ramaderia i Pesca', a department of the Generalitat de Catalunya' (Regional Government of Catalonia), Project No. PCC $68003 / 9$ 
Appendix 1. One-way ANOVA analysis (factor: photograph) of area of specimens to test the reproducibility of photographs. $\mathrm{df}$ effect $=2$; $\mathrm{df}$ residual $=6$ (ns: non significant)

\begin{tabular}{|c|c|c|c|c|}
\hline Specimen & MS factor & MS residual & $F$ & p-value \\
\hline 1 & 433.8 & 1790.2 & 0.24 & $0.80 \mathrm{~ns}$ \\
\hline 2 & 2142.1 & 1025.3 & 2.09 & $0.20 \mathrm{~ns}$ \\
\hline 3 & 3774.1 & 1536.3 & 2.45 & $0.17 \mathrm{~ns}$ \\
\hline 4 & 1971.1 .4 & 5132.2 & 3.84 & $0.08 \mathrm{~ns}$ \\
\hline 5 & 11432.1 & 5719.6 & 2.00 & $0.27 \mathrm{~ns}$ \\
\hline 6 & 1886.1 & 10403.1 & 0.18 & $0.84 \mathrm{~ns}$ \\
\hline 7 & 30689.3 & 13957.9 & 2.19 & $0.19 \mathrm{~ns}$ \\
\hline 8 & 374.8 & 1451.8 & 0.26 & $0.78 \mathrm{~ns}$ \\
\hline 9 & 537.4 & 3087.6 & 0.17 & $0.84 \mathrm{~ns}$ \\
\hline 10 & 293.4 & 2200.8 & 0.13 & $0.87 \mathrm{~ns}$ \\
\hline 11 & 5990.8 & 4451.8 & 1.34 & $0.33 \mathrm{~ns}$ \\
\hline 12 & 7543.4 & 7002.8 & 1.08 & $0.40 \mathrm{~ns}$ \\
\hline 13 & 99447.1 & 144913.1 & 0.69 & $0.54 \mathrm{~ns}$ \\
\hline 14 & 1141.0 & 2071.7 & 0.55 & $0.60 \mathrm{~ns}$ \\
\hline 15 & 721.4 & 11695.4 & 0.06 & $0.94 \mathrm{~ns}$ \\
\hline 16 & 47301.3 & 53409.9 & 0.88 & $0.46 \mathrm{~ns}$ \\
\hline 17 & 49527.4 & 65651.2 & 0.75 & $0.51 \mathrm{~ns}$ \\
\hline 18 & 29554.8 & 45965.2 & 0.64 & $0.55 \mathrm{~ns}$ \\
\hline 19 & 1466.8 & 46174.1 & 0.03 & $0.97 \mathrm{~ns}$ \\
\hline 20 & 13960.3 & 4721.2 & 2.96 & $0.13 \mathrm{~ns}$ \\
\hline 21 & 2280.3 & 1608.2 & 1.42 & $0.31 \mathrm{~ns}$ \\
\hline 22 & 1196.8 & 3188.6 & 0.37 & $0.70 \mathrm{~ns}$ \\
\hline 23 & 38150.8 & 49532.1 & 0.77 & $0.50 \mathrm{~ns}$ \\
\hline 24 & 3574.8 & 62546.1 & 0.06 & $0.94 \mathrm{~ns}$ \\
\hline 25 & 107748.8 & 47832.1 & 2.25 & $0.19 \mathrm{~ns}$ \\
\hline 26 & 160444.0 & 32717.3 & 4.90 & $0.06 \mathrm{~ns}$ \\
\hline 27 & 618544.3 & 622952.6 & 0.99 & $0.42 \mathrm{~ns}$ \\
\hline 28 & 4731419.0 & 1191986.0 & 3.96 & $0.08 \mathrm{~ns}$ \\
\hline 29 & 11364400.0 & 6584030.0 & 1.72 & $0.26 \mathrm{~ns}$ \\
\hline 30 & 29907500.0 & 8676003.0 & 3.44 & $0.10 \mathrm{~ns}$ \\
\hline
\end{tabular}

Appendix 2. One-way ANOVA analysis (factor: photograph) of perimeter of specimens to test the reproducibility of photographs. $\mathrm{df}$ effect $=2 ; \mathrm{df}$ residual $=6$ (ns: non significant; $\cdot \mathrm{p}<0.05$ )

\begin{tabular}{|c|c|c|c|c|}
\hline Specimen & MS factor & MS residual & $F$ & p-value \\
\hline 1 & 3.4 & 18.5 & 0.19 & $0.83 \mathrm{~ns}$ \\
\hline 2 & 5.8 & 10.8 & 0.54 & $0.61 \mathrm{~ns}$ \\
\hline 3 & 1.37 & 10.1 & 0.14 & $0.88 \mathrm{~ns}$ \\
\hline 4 & 194.3 & 188.3 & 1.03 & $0.41 \mathrm{~ns}$ \\
\hline 5 & 8.1 & 158.3 & 0.05 & $0.95 \mathrm{~ns}$ \\
\hline 6 & 2.9 & 12.4 & 0.23 & $0.80 \mathrm{~ns}$ \\
\hline 7 & 0.2 & 9.8 & 0.02 & $0.98 \mathrm{~ns}$ \\
\hline 8 & 6.0 & 19.8 & 0.30 & $0.75 \mathrm{~ns}$ \\
\hline 9 & 42.5 & 137.1 & 0.31 & $0.74 \mathrm{~ns}$ \\
\hline 10 & 48.3 & 45.6 & 1.06 & $0.40 \mathrm{~ns}$ \\
\hline 11 & 53.3 & 43.7 & 1.22 & $0.36 \mathrm{~ns}$ \\
\hline 12 & 85.0 & 153.7 & 0.55 & $0.60 \mathrm{~ns}$ \\
\hline 13 & 3557.6 & 3596.9 & 0.99 & $0.42 \mathrm{~ns}$ \\
\hline 14 & 178.4 & 766.8 & 0.23 & $0.80 \mathrm{~ns}$ \\
\hline 15 & 12.70 & 101.2 & 0.12 & $0.88 \mathrm{~ns}$ \\
\hline 16 & 122.9 & 84.1 & 1.46 & $0.30 \mathrm{~ns}$ \\
\hline 17 & 384.7 & 264.1 & 1.46 & $0.31 \mathrm{~ns}$ \\
\hline 18 & 939.3 & 369.8 & 2.54 & $0.16 \mathrm{~ns}$ \\
\hline 19 & 229.2 & 193.1 & 1.19 & $0.36 \mathrm{~ns}$ \\
\hline 20 & 709.4 & 165.8 & 4.28 & $0.07 \mathrm{~ns}$ \\
\hline 21 & 24.6 & 34.5 & 0.71 & $0.53 \mathrm{~ns}$ \\
\hline 22 & 181.2 & 55.4 & 3.27 & $0.11 \mathrm{~ns}$ \\
\hline 23 & 1621.9 & 274.4 & 5.91 & $0.03^{\circ}$ \\
\hline 24 & 218.8 & 337.3 & 0.65 & $0.55 \mathrm{~ns}$ \\
\hline 25 & 88.3 & 319.5 & 0.28 & $0.77 \mathrm{~ns}$ \\
\hline 26 & 439.0 & 162.3 & 2.70 & $0.14 \mathrm{~ns}$ \\
\hline 27 & 9830.2 & 23805.0 & 0.41 & $0.68 \mathrm{~ns}$ \\
\hline 28 & 153433.0 & 87566.3 & 1.75 & $0.25 \mathrm{~ns}$ \\
\hline 29 & 115241.6 & 59951.7 & 1.92 & $0.22 \mathrm{~ns}$ \\
\hline 30 & 105813.9 & 83694.3 & 1.26 & $0.35 \mathrm{~ns}$ \\
\hline
\end{tabular}


Appendix 3. Specimens boundary category, mean of area and perimeter $(n=9)$ and coefficient of variation $(\mathrm{CV}[\%]=[\mathrm{Sr} / \mathrm{X}] \times$ 100, where $\mathrm{Sr}=\mathrm{MSr}$; $\mathrm{MSr}$ is the mean square error and $X$ is the global mean of the area or perimeter obtained for the outlines of the selected specimens $[\mathrm{n}=9]$ ) for area and perimeter (calculated from the MS residual of the 1-way ANOVA analysis carried out to test the reproducibility of photographs)

\begin{tabular}{|c|c|c|c|c|c|}
\hline Specimen & $\begin{array}{l}\text { Boundary } \\
\text { category }\end{array}$ & $\begin{array}{l}\text { Mean area } \\
\quad\left(\mathrm{mm}^{2}\right)\end{array}$ & $\begin{array}{c}\text { CV }(\%) \\
\text { area }\end{array}$ & $\begin{array}{l}\text { Mean perimeter } \\
\text { (mm) }\end{array}$ & $\begin{array}{l}\text { CV }(\%) \\
\text { perimeter }\end{array}$ \\
\hline 1 & I & 662.1 & 6.4 & 122.9 & 3.8 \\
\hline 2 & I & 1328.4 & 2.4 & 160.8 & 2.0 \\
\hline 3 & I & 1471.6 & 2.7 & 187.1 & 1.7 \\
\hline 4 & I & 1818.6 & 4.0 & 241.0 & 1.5 \\
\hline 5 & [ & 2389.8 & 3.2 & 258.8 & 4.9 \\
\hline 6 & I & 2838.1 & 3.6 & 303.7 & 4.0 \\
\hline 7 & I & 9632.3 & 1.2 & 386.8 & 0.8 \\
\hline 8 & II & 249.4 & 15.3 & 63.6 & 7.0 \\
\hline 9 & II & 375.4 & 14.8 & 78.3 & 13.3 \\
\hline 10 & II & 554.2 & 8.5 & 89.9 & 6.6 \\
\hline 11 & II & 818.4 & 8.1 & 110.9 & 5.7 \\
\hline 12 & II & 972.2 & 8.6 & 120.5 & 9.2 \\
\hline 13 & III & 1160.9 & 32.8 & 136.6 & 4.8 \\
\hline 14 & II & 2363.7 & 1.9 & 159.0 & 31.6 \\
\hline 15 & II & 2435.8 & 4.4 & 285.7 & 10.0 \\
\hline 16 & [I & 4006.7 & 5.8 & 308.6 & 3.4 \\
\hline 17 & II & 8022.4 & 3.2 & 478.6 & 1.9 \\
\hline 18 & II & 13518.1 & 1.6 & 761.4 & 2.6 \\
\hline 19 & II & 15840.4 & 1.4 & 867.4 & 1.9 \\
\hline 20 & III & 284.0 & 24.2 & 870.0 & 1.6 \\
\hline 21 & III & 366.0 & 11.0 & 88.8 & 13.9 \\
\hline 22 & IIII & 905.8 & 6.2 & 160.3 & 4.5 \\
\hline 23 & III & 2525.4 & 8.8 & 259.8 & 6.2 \\
\hline 24 & III & 2700.4 & 9.3 & 281.2 & 4.2 \\
\hline 25 & III & 3265.4 & 6.7 & 284.4 & 6.9 \\
\hline 26 & III & 3544.3 & 5.1 & 333.5 & 5.9 \\
\hline 27 & III & 4699.2 & 16.5 & 1147.4 & 13.7 \\
\hline 28 & IIII & 15576.2 & 7.0 & 2714.5 & 11.0 \\
\hline 29 & III & 101467.2 & 2.6 & 4456.5 & 5.4 \\
\hline 30 & III & 113755.7 & 2.6 & 4644.7 & 6.0 \\
\hline
\end{tabular}

\section{LITERATURE CITED}

Ayling AL (1983) Growth and regeneration rates in thinly encrusting Demospongiae from temperate waters. Biol Bull 165:343-352

Bak RPM, Sybesma J, van Duyl FC (1981) The ecology of tropical compound ascidian Trididemnum solidum. II. Abundance, growth and survival. Mar Ecol Prog Ser 6: $4.3-52$

Coma R (1994) Evaluación del metabolismo de dos suspensivoros bentónicos marinos: Orthopyxis crenata y Paramuriced clavata. PhD thesis, University of Barcelona

Cowan ME (1981) Field observation of colony movement and division of the ascidian. Didemmum molle. Mar Ecol Prog Ser 6:335-337

Dayton PK (1979) Observations of growth, dispersal and population dynamirs of some sponges in McMurdo Sound, Antarctica. Coll Int CNRS 291:270-282

Fabricius KE (1995) Slow population turnover in the soft coral genera Sinularia and Sarcophyton on mid-and outer-shelf reefs of the Great Barrier Reef. Mar Ecol Prog Ser 126: $145-152$

Garrabou J (1997) Structure and dynamics of north-western Mediterranean rocky benthic communities along a depth gradient: a Geographical Information System (GIS) approach. PhD thesis, Universitat de Barcelona

Hughes RN (1989) A functional biology of clonal. animals. Chapman and Hall, London

Hughes RN, Cancino JM (1985) An ecological overview of cloning in Metazoa. In: Jackson JBC, Buss LW, Cook RE (eds) Population biology and evolution of clonal organisms. Yale University Press, New Haven, p 153-186

Hughes TP, Jackson JBC (1985) Population dynamics and life histories of foliaceous corals. Ecol Monogr 55(2):141-166

Jackson JBC (1977) Competition on marine hard substrata: the adaptive significance of solitary and colonial strategies. Am Nat III:743-767

Jackson JBC (1979) Morphological strategies of sessile animals. In: Larwood G, Rosen BR (eds) Biology and systematics of colonial arganisms. Academic Press, London, p $499-555$

Johnson LB (1990) Analyzing spatial and temporal phenomena using geographical information systems. Landscape Ecol 4(1):31-43

Johnston CA (1992) GIS technology in ecologı.cal research. In Encyclopedia of earth system science, Vol 1 Academic Press, London, p 329-346

Kienast F (1993) Analysis of historic landscape patterns with a Geographical Information System - a methodological outline. Landscape Ecol 8(2):103-118

Nandakumar K, Tanaka M, Kikuchi T (1993) Interspecific competition among fouling organisms in Tomioka Bay, Japan. Mar Ecol Prog Ser 94:43-50

Sebens KP (1986) Spatial relationships among encrusting marine organisms in the New England subtidal zone. Ecol Monogr 56(1):73-96

Sebens KP (1987) The ecology of indetermunate growth in animals. Annu Rev Ecol Syst 18:371-407 
Stocker LJ (1991) Effects of size and shape of colony on rates of fission, fusion, growth and mortality in a subtidal invertebrate. J Exp Mar Biol Ecol 149:161-175

Turner MG (1989) Landscape ecology: the effect of pattern on process. Annu Rev Ecol Syst 20:171-197

Turon X, Becerro MA (1992) Growth and survival of several

Editorial responsibility: Otto Kinne (Editor),

Oldendorf/Luhe, Germany ascidian species from Northwestern Mediterranean. Mar Ecol Prog Ser 82:235-247

Vago R, Vago E, Achituv Y, Ben Zion M, Dubinsky Z (1994) A non-destructive method for monitoring coral growth affected by anthropogenic and natural long term changes. Bull Mar Sci 55(1):126-132

Submitted: August 28, 1997; Accepted: July 31, 1998

Proofs received from author(s): October 19, 1998 